\title{
REDES ENUNCIATIVAS NO ENSINO DA LÍNGUA PORTUGUESA
}

\author{
Luiz. Francisco Dias*
}

RESUMO: O presente texto tem como objetivo oferecer subsídios para o trabalho com linguagem na escola, destacando as redes enunciativas como um profícuo caminho para o desenvolvimento de projetos didáticos, voltando o olhar para o sentido na produção da linguagem pelas articulações de palavras do enunciado. A exploração do ponto de vista se dá como uma proposta a partir do enfoque às atividades com elaboração de redes, o que propicia o destaque à proposta de trabalho com a linguagem em um campo interdisciplinar. Apresentam-se sugestões de atividades por meio das formações nominais e das redes enunciativas, o que se mostra, enfim, um produtivo caminho para o professor em sua tarefa de propiciar experiências de contato com a produção de sentidos nos anos finais do Ensino Fundamental.

PALAVRAS-CHAVE: Rede enunciativa; Ensino do português, Tecnologia; Ponto de vista.

\section{Introdução}

O presente texto se destina a oferecer subsídios para o trabalho com a linguagem na escola, principalmente nas últimas séries do ensino fundamental. Pretendemos fornecer elementos para a elaboração de projetos de ensino que possam explorar o sentido na linguagem pelas articulações das palavras do enunciado.

Ao mesmo tempo, pretendemos levar ao professor a possibilidade de explorar a interdisciplinaridade, por meio relação entre a constituição da história e o funcionamento da linguagem. A nossa hipótese é a de que, quando estamos mostrando a significação da linguagem, estamos, ao mesmo tempo, mostrando como se constrói a história.

Para isso, propomos que uma boa metodologia para desenvolver essa concepção de trabalho em um projeto didático é a utilização de redes enunciativas.

\footnotetext{
* Professor Titular da Universidade Federal de Minas Gerais (UFMG). Doutor em Linguística pela Universidade Estadual de Campinas (Unicamp). Pesquisador bolsista do Conselho Nacional de Desenvolvimento Científico e Tecnológico (CNPq). Desenvolve pesquisas em semântica e em história das ideias linguísticas. É autor das obras Os sentidos do idioma nacional (1995) e Enunciação e relações linguísticas (2018), ambas publicadas pela Pontes Editores. 
O conceito de rede enunciativa tem sido desenvolvido no âmbito do Grupo de Estudos da Enunciação da UFMG nos últimos anos, e tem como ponto de partida o texto de Dias (2006), no qual criticamos a prática da exemplificação na escola efetuada por meio de exemplos isolados no estudo dos conhecimentos linguísticos. Nomeamos 'exemploilha' esse tipo de exemplo. Propomos então trabalhar com o conceito de 'exemplo-colmeia' como metáfora para se conceber uma integração de diversas ocorrências da língua, no sentido de apoiar conceitos apresentados didaticamente aos alunos.

Em Dias (2018), utilizamos o termo "rede enunciativa" como substituto de "exemplo-colmeia". Nos termos da obra de 2018,

A constituição de uma rede enunciativa envolve a formação de contrastes entre a construção linguística em estudo e outras construções com estruturas semelhantes e palavras iguais, no sentido de permitir a percepção dos domínios de mobilização que a enunciação sustenta. Essas construções outras, trazidas para a rede enunciativa, são construídas pelo próprio pesquisador e/ou podem também ser buscadas em usos efetivos, como no Google e nos bancos de dados que abrigam usos orais e escritos da nossa língua. (DIAS, 2018, p. 35)

E ainda:

podemos conceituar rede enunciativa como um procedimento de demonstração das relações entre unidades articuladas, por meio de semelhanças e diferenças entre construções linguísticas. (DIAS, 2018, p. 36)

Em suma, utilizamos redes enunciativas para criar um ambiente de observação das relações de sentido na linguagem por meio das articulações entre as unidades linguísticas (substantivo, verbo, advérbio). Enfim, a rede enunciativa é uma técnica de demonstração das relações de sentido de um enunciado.

Acreditamos que a proposição de projetos de ensino com base em redes enunciativas atende aos fundamentos da nova BNCC, nos seguintes termos:

Assume-se aqui a perspectiva enunciativo-discursiva de linguagem, já assumida em outros documentos, como os Parâmetros Curriculares Nacionais (PCN), para os quais a linguagem é "uma forma de ação interindividual orientada para uma finalidade específica; um 
processo de interlocução que se realiza nas práticas sociais existentes numa sociedade, nos distintos momentos de sua história" (BRASIL, 1998, p. 20).

A constituição de redes enunciativas é, assim, uma forma de interlocução de pontos de vista sociais incorporados nos enunciados.

O texto abordará inicialmente o papel da relação e dos pontos de vista na constituição da história. A seguir, apresenta um conjunto de redes enunciativas voltadas para o sentido atual de tecnologia. Essa análise será orientada para algumas projeções no ensino da língua portuguesa, e será seguida das considerações finais.

\section{História: relação e pontos de vista}

A palavra 'história' é comum no nosso dia-a-dia. Digo que alguém contou uma história interessante; ouço alguém falar que sua bistória de vida dava um livro; revelo que minha bistória com determinada pessoa começou no primeiro Natal desta década. Temos também uma palavra derivada de 'história' que frequenta o nosso cotidiano, quando um apresentador de telejornal afirma que ontem foi um dia bistórico na política brasileira.

Quando dizemos que a história de uma pessoa dá um livro, estamos considerando, por exemplo, o fato de que a pessoa passou por tantos e tantos problemas na vida, e que, mesmo assim, venceu. Nós costumamos achar surpreendente que problemas "insolúveis" sejam superados. E que muitas pessoas gostariam de saber como se resolvem problemas e se produzem mudanças radicais na vida. Escrever uma história de vida exige que a gente exponha as causas dos problemas, relacione esses fatos problemáticos, as adversidades, e conecte as ações realizadas pelas pessoas no sentido da superação.

Da mesma maneira, contar uma boa história, seja real ou fictícia, envolve criar boas relações entre episódios verídicos, ou entre ações fictícias. Vamos fazer uma breve leitura em um fragmento de história do cotidiano para observar essas relações. 
(...) fui com meus pais visitar minha tia. Eu falava pouco, quase sempre ficava em silêncio. Todos estavam sentados na sala de estar, enquanto eu tentava atrair a atenção de mamãe. Ela conversava ativamente com os convidados e mal notava a minha presença. Então saí da sala e, alguns minutos depois, voltei com uma panela coberta por uma tampa. Sem dizer nada, entreguei o objeto para minha tia (...)

Esse é um trecho de uma história contada por um adulto lembrando do seu tempo de criança.

Observemos que a visita à casa da tia dá início a uma sequência de episódios relacionados:

a) a ida à casa da tia

b) a tentativa de falar alguma coisa para a mãe

c) a saída da sala

d) o retorno à sala com uma panela

e) a entrega da panela para a tia

A relação entre esses episódios atrai a nossa atenção e cria curiosidade sobre a continuação da sequência narrativa. Um bom contador de história sabe que, para atrair interesse em uma narrativa, é importante investir na relação entre suas partes, de maneira que um episódio atraia outro, instigando o interesse pelo acompanhamento da história.

Vimos que é importante a relação entre episódios na construção de uma história. Igualmente importante na elaboração de histórias é o ponto de vista.

A expressão 'ponto de vista' é normalmente abordada em nossas escolas no ensino de geografia e de geometria. Observemos um fragmento de atividade escolar que explora a noção de ponto de vista: 
Figura 1 - Exploração da noção de ponto de vista em atividade escolar

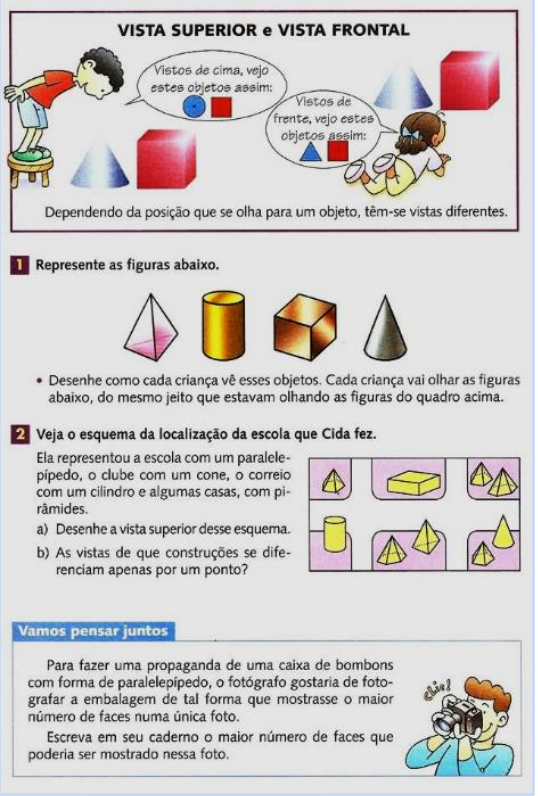

Fonte: web

Como podemos conceber a noção de 'ponto de vista' numa história do cotidiano? $\mathrm{Na}$ história cujo fragmento apresentamos acima, a narrativa é apresentada do ponto de vista da pessoa que relembra o seu passado quando criança. Como seria esse fragmento da história se ela fosse contada pela mãe da criança? Podemos tentar fazer esse exercício imaginativo:

(...) fui com as crianças visitar minha irmã. Meu filho mais novo falava pouco, quase sempre ficava em silêncio. Todos estavam sentados na sala de estar. Eu conversava ativamente com os convidados. Não percebi que ele saiu da sala. Só me dei conta dele quando retornou com uma panela coberta por uma tampa. Sem dizer nada, entregou o objeto para minha irmã (...)

Observemos que a história contada pela mãe tem menos "ação", justamente porque ela se movimenta menos na história. As relações nela construídas são estabelecidas por meio do olhar da mãe, que fica sentada, e só percebe o filho quando ele entra na sala com um objeto inesperado. 
Tomando por base o mesmo fragmento, caso essa histórica fosse contada do ponto de vista da tia, teríamos uma sequência ainda mais reduzida:

(...) recebi em casa minha irmã com meus sobrinhos. O mais novo deles falava pouco, quase sempre ficava em silêncio. Todos estavam sentados na sala de estar. Eu conversava ativamente com os convidados, quando ele entrou na sala com uma panela coberta por uma tampa e me entregou. (...)

Com efeito, o alcance do olhar da tia (ponto de vista) não permite a ela apresentar muitos episódios para estabelecer relações na história.

Vimos que as relações e os pontos de vista são cruciais nas histórias do cotidiano. E na escola? Como a história é levada aos alunos? Relações e pontos de vista são igualmente importantes?

Ela efetivamente entra no currículo: temos uma disciplina com esse nome. No ambiente escolar do ensino básico, todos nós passamos pela disciplina de "História". Por meio dela, conhecemos fatos que mudaram o mundo, pessoas que foram importantes para o destino dos povos etc.

A vinda da Família Real para o Brasil em 1808 foi um fato histórico importante, e todos os livros didáticos de história fazem uma apresentação dele. A parte em que esse fato é narrado apresenta títulos que diferem de um livro para outro. Em um deles o título é: “A vinda da família real para o Brasil” (FERNANDES, 2018, p. 114). Em outro, o trecho é intitulado "A transferência da Corte portuguesa" (MINORELLI; CHIBA, 2018, p. 100). Embora a mobilidade do Reinado esteja marcada nos verbos vir e transferir, essa relação entre a nação portuguesa e a colônia é concebida por dois pontos de vista diferentes.

Em uma, o historiador se coloca do ponto de vista do Brasil ao narrar. A forma verbal 'vinda' demonstra que ele concebe a movimentação do Rei a partir de quem está aqui no Brasil e fala sobre o Rei da perspectiva da sua vinda de lá (Europa). Um livro de história escrito por um historiador português para os estudantes portugueses não apresentaria esse título, obviamente. Já o outro título (“A transferência da Corte Portuguesa”) não marca o lugar de onde se narra a história. Poderia, dessa maneira, constar em um livro de história em Portugal. 
Essa diferença de pontos de vista, além de estar no título, também se encontra no texto da narrativa histórica, inclusive com aquela diferenciação, e ainda mais marcante: "a Corte portuguesa, composta de cerca de 15 mil pessoas, veio para o Brasil" (COTRIM; RODRIGUES, 2018, p. 100); "Embarcaram para a América cerca de 15 mil pessoas" (CAMPOS, CLARO; DOLHNIKOFF, 2019, p. 137). No primeiro trecho, novamente o verbo "vir" situa o Brasil como ponto de vista da narração histórica. No segundo trecho, a perspectiva do embarque para a América constitui um ponto de vista europeu. Sendo assim, o segundo trecho poderia ser parte de um livro de história lusitano, o que não ocorreria com o primeiro trecho.

Seja na escola, seja nas cenas diárias fora da escola, estamos relacionando fatos e apresentando essas relações de um ponto de vista.

Até agora, apresentamos amostras de narrativas históricas voltadas para o passado. No entanto, a palavra 'história' pode ser usada também para falarmos do presente, afinal estamos construindo a história no nosso dia-a-dia. A história do presente é captada pelos nossos enunciados. São os nossos enunciados que captam as relações e os pontos de vista. A seguir, veremos essa questão a partir de redes enunciativas.

\section{Redes enunciativas: tecnologia e pontos de vista históricos}

a) A tecnologia: do passado para o presente

Uma das imagens mais recorrentes na mídia informal, relativa à evolução da espécie humana, não é aceita pela ciência na atualidade.

Figura 2 - Iconografia linear da evolução

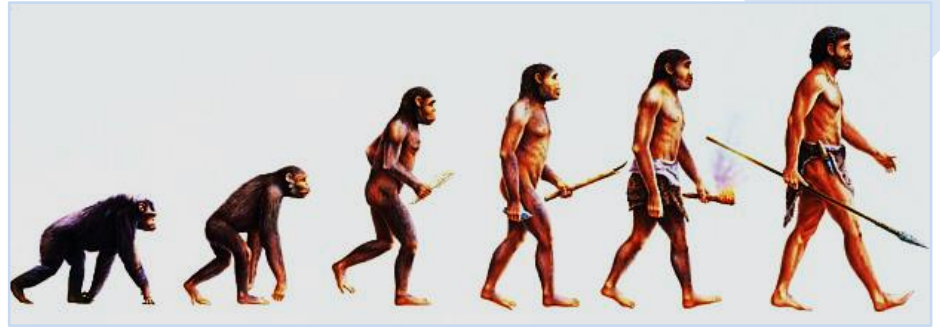

Fonte: Veja 
Essa representação da evolução humana foi concebida no Séc. XIX, e apresenta uma perspectiva linear da evolução. Trata-se de uma visão considerada ultrapassada atualmente. $\mathrm{Na}$ verdade, tivemos períodos de convivência de espécies diferentes de indivíduos do gênero Homo. Há muitos estudos que apontam a convivência entre neandertais e homo sapiens, que até interagiram em determinado período da história. Por isso, não uma linearidade na linha histórica da evolução.

No entanto, fundamentadas no senso comum, as pessoas exploram essa imagem por meio de variados memes, charges, e outras representações. Essa exploração se expande bastante nas páginas da internet e nas redes sociais.

A seguir, vamos analisar algumas dessas representações. Evidentemente, não nos interessamos pela evolução passada do homem. Isso é uma tarefa de pesquisadores de outras áreas do conhecimento. O nosso foco está no modo como se enuncia, por meios verbais e não verbais, o estágio atual do homem nesta representação evolutiva. Especificamente, estamos interessados nos pontos de vista pelos quais enunciamos o presente e o futuro do homem frente ao avanço da tecnologia. Com essa análise, pretendemos mostrar formas de trabalho com a linguagem na escola, explorando a interdisciplinaridade e a multimodalidade.

Apresentaremos quatro redes enunciativas. Em cada uma delas, teremos três fragmentos textuais retirados da internet contendo enunciados com palavras e expressões relacionadas a tecnologia. Completa cada uma das redes uma expressão enunciativa em modalidade visual, também retirada da internet.

b) A tecnologia na evolução humana: enunciando o presente

Observemos incialmente a Figura 3, em que analisamos enunciados que apontam a relevância da tecnologia da atualidade. 
Figura 3 - Rede enunciativa: relevância da tecnologia na atualidade

A tecnologia na área da saúde permite a integração das informações, facilitando o trabalho dos profissionais envolvidos.

A internet e a tecnologia da informação trazem consigo uma profusão inimaginável de informações ao alcance dos dedos. A curiosidade e a criatividade ultrapassam os limites físicos.

Advogados, magistrados e tribunais estão cada vez mais empregando tecnologia em seus trabalhos, para torná-los mais profundos e precisos.

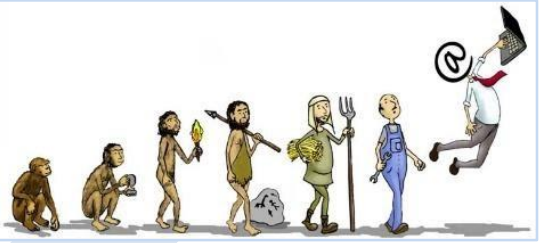

Fonte: autoria própria

A rede enunciativa apresenta uma sequência de três fragmentos textuais. Neles, a palavra 'tecnologia' contrai relação com outras, articulando-se sintaticamente nos enunciados, como sujeito dos verbos 'permitir' e 'trazer' e como objeto do verbo 'empregar'. Esses três verbos permitem associar tecnologia com integração de informação, facilidade de trabalho, informação ao alcance de todos, criatividade, curiosidade, trabalho de advogados, magistrados e tribunais mais profundo e preciso.

Dessa maneira as relações que a palavra "tecnologia" estabelece nos nossos enunciados são indicadoras da sua significação.

No quadro final da rede, temos um enunciado visual, representando um homem que se projeta para o alto, por meio de um equipamento eletrônico, conectado ao mundo virtual. A elevação gradual dos corpos na representação icônica da evolução culmina com uma variante da espécie humana afetada pelos recursos tecnológicos.

Esse enunciado visual desenvolve o mesmo ponto de vista sobre a tecnologia que vimos nos enunciados verbais: a relevância da tecnologia na atualidade. Portanto, uma visão positiva.

Quando falamos sobre a melhoria do trabalho com a tecnologia, estamos desenvolvendo um ponto de vista histórico sobre ela.

Observemos agora outro "olhar" para a tecnologia: 
Figura 4 - Rede enunciativa: distorção da tecnologia na atualidade

Avanço tecnológico no sistema produtivo causará cada vez mais desemprego.

A tecnologia dá a impressão de que estamos interagindo o tempo todo, mas estudantes estão cada vez mais perdendo o hábito de conversar e interagir socialmente por meios off-line. Manter uma conversa pessoalmente está se tornando uma tarefa difícil e evitada pelas crianças de hoje.

A tecnologia fez com que os estudantes se tornassem cada vez mais irritados quando têm que deixar os seus aparelhos e jogos de lado.

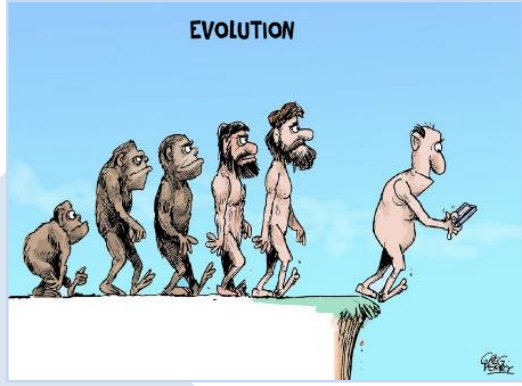

Fonte: autoria própria

Nessa rede, avanço tecnológico e tecnologia estão articulados nos enunciados de forma a carrear um valor negativo para as duas expressões. No primeiro enunciado, o avanço tecnológico é causa de desemprego; no segundo, a tecnologia produz impressões de interação, mas que não é verdadeira; no terceiro, a falta de aparelhos tecnológicos causa irritação em jovens.

Por sua vez, da mesma maneira que no enunciado visual da rede anterior, temos aqui um homem também conectado ao mundo virtual, por meio de equipamento eletrônico. No entanto, nesta charge, ele não se projeta para o alto, mas para um despenhadeiro, ou um profundo buraco. Trata-se de uma visão negativa da tecnologia.

Como podemos observar, a tecnologia entra nos enunciados dessa rede orientada por um ponto de vista contrário ao da primeira rede. Os fatores negativos estão determinando a palavra nos enunciados da rede, numa relação de articulação, de forma a produzir um ponto de vista da tecnologia na história, orientado pela distorção. 
c) A tecnologia na evolução humana: enunciando o futuro

Agora, vamos analisar duas redes enunciativas que concebem a tecnologia no futuro. Nestas redes, o nosso foco não será na palavra 'tecnologia', ou numa expressão em que ela é componente. Vamos centrar em instrumentos tecnológicos, como 'robô', 'próteses' e 'máquinas'.

Figura 5 - Rede enunciativa: eficácia da tecnologia no futuro

Quando os trabalhos que realizamos hoje de forma mecânica e repetitiva forem delegados aos robôs, seja ele de automação ou de artificialização da inteligência, teremos a liberdade para viver de forma mais humanizada, priorizando nas nossas produções de riquezas o criar, cuidar, conhecer, compartilhar, comunicar, curar.

A produção de próteses ficará tão boa e avançada em dez anos que elas poderão realmente dar "novas habilidades" para as pessoas.

Os robôs irão revolucionar o mercado de trabalho nos próximos anos. Mas não vão acabar com os empregos.

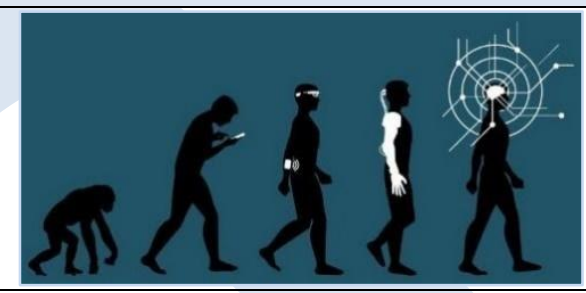

Fonte: autoria própria

Nessa rede enunciativa, o primeiro enunciado apresenta 'robô' como articulador de transformação de uma vida de trabalho mecânico e repetitivo atual para uma vida bumanizada no futuro. No segundo enunciado, 'próteses' articula a inserção de novas habilidades para as pessoas no futuro. No terceiro, por sua vez, novamente 'robôs' é uma unidade do enunciado que estabelece a base para articular a revolução no mercado de trabalho, e ainda conservando o emprego dos humanos.

Essas articulações trazem a concepção positiva de um futuro identificado pelo uso intenso de instrumentos tecnológicos, como robôs e próteses.

Esse ponto de vista está também presente no componente não verbal da rede. Novamente, temos uma ancoragem ou sustentação no passado. Desta vez, essa ancoragem projeta um futuro no âmbito da tecnologia. A progressividade da evolução chega nas duas 
figuras finais da sequência com um homem cujo corpo é mesclado pela prótese e cuja mente é conectada, extrapolando os limites do cérebro. Trata-se de uma visualização do ponto de vista da relevância da tecnologia no futuro, em que a mente humana incorpora completamente as funções tecnológicas.

Observemos a última rede enunciativa.

Figura 6 - Rede enunciativa: descontrole da tecnologia no futuro

Há preocupações semelhantes quanto ao impacto de companheiros robotizados na ponta oposta da vida: como eles afetarão a capacidade de crianças pequenas para interagir e fazer amizades com pessoas reais.

As faculdades de aprendizagem automática das máquinas alimentadas por quantidades colossais de informação torná-las-ão, em breve, imprevisíveis"; e "a essa imprevisibilidade soma-se a sua crescente autonomia que faz com que nos escapem e exerçam um domínio cada vez maior sobre o homem.

Capazes de analisar os comportamentos de seus interlocutores, esses robôs podem decifrar suas emoções e modificar seus comportamentos em consequência dessa habilidade.

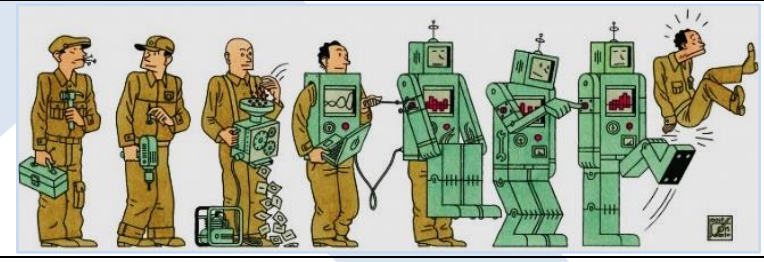

Fonte: autoria própria

Nessa rede enunciativa, no primeiro enunciado, em um cenário de futuridade, 'companheiros robotizados' constituem a base para a articulação com afetar a capacidade de crianças interagirem e faz̧erem amizades. No segundo enunciado, 'máquinas de informação' se articulam com capacidade imprevisivel e autonomia com domínio sobre o homem. No terceiro, por sua vez, 'robôs' formam uma unidade de sustentação articulatória com capacidade de decifrar emoções humanas e assim modificar nossos comportamentos.

Por sua vez, no enunciado visual, a absorção "metálica” gradual do corpo humano culmina com uma expulsão do componente propriamente humano do corpo, representado pelo chute que o robô aplica no homem. 
Como podemos perceber, trata-se da configuração de um ponto de vista contrário àquele da rede anterior. Neste caso, ao invés da eficácia dos produtos tecnológicos, temos uma concepção de descontrole desses produtos.

Um balanço da presença dos enunciados visuais nas redes reforça esses pontos de vista, observando-se a relação entre o homem e os produtos tecnológicos. Nessas figuras, as formas do corpo são reveladoras dessa relação. Por exemplo, se a elevação corporal é considerada uma evolução, temos um homem que se eleva ainda mais por meio da tecnologia.

Essas formas corporais se apresentam conforme determinação da tecnologia, denunciado pontos de vista na trama histórica. Por sua vez, nos enunciados verbais, as articulações que as palavras contraem no âmbito do enunciado é que demarcam esses pontos de vista.

Torna-se fundamental observamos a relação entre as formas do corpo do homem e as articulações das palavras no enunciado. Com isso, podemos compreender os pontos de vista que se integram à história de nós mesmos que estamos construindo no presente.

\section{Redes enunciativas, enunciação e história: projeções para o ensino de língua}

Como informamos na introdução, o presente texto pretende oferecer elementos para a constituição de um projeto de ensino no sentido de complementar o conteúdo de livros didáticos de língua portuguesa nas séries finais do ensino fundamental. Nesse projeto, a reflexão sobre a língua portuguesa, e mais particularmente sobre o sentido na linguagem, terá uma articulação com o ensino de história.

O desenvolvimento da ideia aqui exposta, em forma de sequências didáticas, pode favorecer a elaboração de diversas atividades com o objetivo de fomentar a discussão sobre a constituição da história pela enunciação. Todas elas devem levar o aluno a compreender a linguagem pelas articulações entre as unidades do enunciado.

Uma das maneiras de propor atividades que se situam na mesma direção do que apresentamos sobre a tecnologia seria uma proposta para que o aluno elabore enunciados que possam se situar nas redes enunciativas apresentadas. 
Outra maneira de fomentar a participação do aluno no quadro do problema da tecnologia envolve solicitar ao aluno que faça a relação entre as redes e palavras que produzem formações nominais do tipo homo digitus, homo machina, homo deus, homo liturgicus, homo economicus, homo civilis, homo urbanus, homo juridicus, homo pacificus, homo fofoquencis. Todos esses termos encontram-se disseminados na internet. Acreditamos que será um exercício produtivo para o aluno estabelecer relações entre esses termos e os termos científicos já consagrados: homo erectus, homo sapiens, homo habilis.

Nessa linha de ideias, as atividades podem envolver a elaboração de redes enunciativas com enunciados verbais que possam auxiliar na compreensão das formações nominais apresentadas acima. Cada uma das formações nominais participaria de uma rede enunciativa com enunciados que se situam no mesmo ponto de vista. Por exemplo: para homo urbanus, o aluno seria solicitado a criar ou buscar na internet enunciados que possam identificar a característica urbana do homem. Além disso, ele pode desenhar ou buscar enunciados visuais que também se situem nessa mesma perspectiva, a da natureza urbana do homem moderno. Além disso, o aluno pode usar da sua criatividade e criar outras formações nominais "homo ...", nas quais ele possa identificar pontos de vista no nosso tempo histórico ou de um futuro projetado.

Enfim, um amplo leque de possibilidades se abre com a perspectiva de constituição de redes enunciativas no ensino. Elas permitem o agrupamento de enunciados que abrigam palavras e expressões socialmente importantes. Elas também proporcionam a visão de história como uma dinâmica social e que está sempre em construção na medida em que enunciamos. Ao enunciar, tomamos posição frente aos pontos de vista sobre o mundo.

\section{Considerações finais}

Vimos que, por meio da análise dos enunciados, podemos flagrar os pontos de vistas que constituem a história. Para isso, buscamos analisar enunciados que abordam a tecnologia e os produtos tecnológicos que impactam a nossa vida na contemporaneidade. 
Portanto, trata-se de uma das maneiras que temos na sociedade atual para "olhar" para a tecnologia. Um olhar compartilhado socialmente é um ponto de vista que constrói a história do nosso tempo.

As relações que se produzem nas unidades do enunciado são relações da construção de um olhar sobre o mundo, portanto, são relações que constroem a história. A história se constrói nos modos como enunciamos no cotidiano, a partir da vivência em sociedade. A pluralidade social é que permite a construção histórica.

A história se desenvolve no conflito de pontos de vista. Estamos em história, seja enunciando o passado, o presente ou o futuro. A concepção de "ponto de vista" é essencial no desenvolvimento do conceito de referencial histórico que desenvolvemos para a elaboração de um modelo de análise semântica de natureza enunciativa. Em Dias (2018), esse conceito e esse modelo são apresentados em detalhe.

Procuramos demonstrar que a escrita da história não está restrita ao falar do passado. Na enunciação, estamos em meio ao histórico, seja enunciando o passado, o presente ou o futuro. A enunciação da história é a enunciação do cotidiano, elaborada sobre qualquer tema.

Aqui neste artigo, exemplificamos essa enunciação com a noção de tecnologia. A enunciação da história, como enunciação do cotidiano, envolve relações, e elas se refletem nas articulações dos enunciados.

Especificamente, estamos interessados nos pontos de vista pelos quais enunciamos o presente e o futuro do homem frente ao avanço da tecnologia. A nossa ideia é de que esses modos de enunciar o homem revelam a construção da história.

A rede enunciativa é uma pequena amostra de uma infinidade de outros enunciados, visuais ou verbais, que desenvolvem pontos de vista da tecnologia.

Acreditamos que a utilização das redes enunciativas no ensino pode ser bastante produtiva para o aluno desenvolver um olhar sobre as articulações da linguagem, no sentido de buscar a compreensão do nosso lugar na história. Com isso, buscamos trabalhar na escola o epilinguístico ao invés do metalinguístico. 


\section{ENUNCIATIVE NETWORKS IN THE TEACHING OF THE PORTUGUESE LANGUAGE}

ABSTRACT: This text aims to offer subsidies for work with language in schools, highlighting enunciative networks as a fruitful path for the development of didactic projects, focussing on the meaning in language production through the articulation of words enunciated. Exploring a point of view comes about as a proposal to focus on activities with the elaboration of networks, which fosters the emphasis on working with language in an interdisciplinary field. The work with suggested activities coming from nominal structures and enunciative networks proves to be a productive path for a teacher seeking to provide experiences involving the production of meaning in the final years of Secondary Education.

KEYWORDS: Enunciative Network; Portuguese teaching; technology; point of view

\section{REFERÊNCIAS}

BRASIL. Base Nacional Comum Curricular (BNCC). Educação é a Base. Brasília, MEC/CONSED/UNDIME, 2018. Disponível em: http://basenacionalcomum.mec.gov.br/

DIAS, L. F. Enunciação e relações linguísticas. Campinas: Pontes, 2018.

Novas Perspectivas no ensino de gramática na escola: o estatuto do exemplo em questão. In: OLIVEIRA, S.E. e SANTOS, J.F. (orgs). Mosaico de linguagens. Campinas: Pontes/CELLIP, 2006, p.43-53.

MINORELLI, C. T.; CHIBA, C. H. F. Convergências história: ensino fundamental. $8^{\circ}$ ano. Livro do Professor. 2 ed. São Paulo: Edições SM, 2018.

FERNANDES, A. C. (org.). Projeto Araribá mais história. $8^{\circ}$ ano. Livro do Professor. São Paulo: Moderna, 2018.

CAMPOS, F. de; CLARO, R.; DOLHNIKOFF, M. História: escola e democracia. $8^{\circ}$ ano. Livro do Professor. São Paulo: Moderna, 2019.

COTRIM, G.; RODRIGUES, J. Historiar. $8^{\circ}$ ano. Livro do Professor. 3. ed. São Paulo: Saraiva, 2018.

Recebido em: 30/05/2020.

Aprovado em: 30/06/2020. 